\title{
Primary care interventions to encourage organ donation registration: a systematic review
}

\section{Abstract}

Background: Previous research has proposed that primary care interventions to increase organ donation rates can help address the discrepancy between organ donation rates and the number of patients awaiting transplant. However, no systematic review has been conducted to examine interventions in this setting.

Objective: To synthesise evidence from previous organ donation interventions conducted in a primary care setting.

Methods: Six databases and grey literature were systematically searched between November 2016 and July 2017. Inclusion criteria included English language, studies published after the year 2000 and unpublished studies. A quality assessment and narrative synthesis was conducted.

Results: Eight studies met the inclusion criteria, all of which examined actual organ donor registration as their primary outcome. Seven interventions increased registration to be an organ donor. Successful interventions utilised active methods of participant engagement that encouraged donation at the point of patient contact.

Discussion: Despite the small pool of studies that met the inclusion criteria, the results suggest primary care interventions could produce promising results for increasing organ donation registration. However, additional higher quality studies are required before firm conclusions can be made. Barriers to implementation were also found and suggest the 
feasibility of a primary care environment for organ donation intervention should be investigated. 


\section{Background}

Worldwide there is a disparity present between available organs and the number required for transplant [1]. During the period $1^{\text {st }}$ April 2016 to $7^{\text {th }}$ April 2017, 6476 people living in the United Kingdom (UK) were in need of an organ yet only 3712 transplants were carried out during this time [2]. A similar pattern is present in the U.S.A, as of $18^{\text {th }}$ July 2017116933 candidates were awaiting transplant and only 17,155 were carried out in 2017 [3]. Many countries, like the U.S.A and England, adopt an opt-in method for donation, where consent for donation is not assumed, donation wishes of the deceased are acknowledged either by registry in life and/or by family consent after death [4]. Registers are held in these countries which record whom wishes to be an organ donor [4]. Being a member of a registry gives an official method for acknowledging wishes and increases the likelihood of family consent [5]. Opt-out systems however, assume a preference for donation unless a person chooses to opt-out [4], adopted in Austria, Argentina and France for example [4]. Two types of opt-out system exist, 'hard' or 'soft' with soft requiring family consent to proceed with donation [4]. The majority of 'opt-out' countries use the 'soft' method, therefore the importance of intervention is still highlighted, due to the importance of family consent [4].

Several interventions have been developed to improve rates of organ donation and reduce the disparity between need and actual transplant [6]. These focus on targeting registration and/or discussing organ donation wishes with family members [7-14]. Internationally, these have been implemented using numerous techniques and settings. Many systematic reviews on interventions in these areas have been carried out (e.g. school based interventions [9], interventions targeting healthcare professionals [7], ethnic minority focused interventions 
[14]. However, no review has yet been published focusing solely on interventions in the primary care setting. By systematically reviewing these the most effective methods, strategies and theory can be used to base primary care studies and interventions on in the future.

Primary care is the main point of contact to healthcare systems [15], therefore interventions in this setting allow for a high level of exposure to diverse populations of patients. For example, in the UK at present, asking patients to join the NHS ODR only occurs at registration at a general practice (GP) clinic, responsible for $9 \%$ of the total new registrations [16]. By developing a new primary care intervention, at least partially based on the results of this review, it is anticipated that recruitment to registers and family consent levels can be boosted, particularly if all patients are targeted as opposed to only new registrants.

\section{Objectives}

To synthesise evidence from previous organ donation interventions conducted in a primary care setting and determine their effectiveness in improving both primary and secondary outcomes.

\section{Method}

Inclusion and exclusion criteria

Included in this review were primary studies of interventions, published and unpublished, in the English Language. Peer reviewed journals, conference proceedings and theses were all included. Any intervention aimed at encouraging organ donation conducted in a primary care setting regarding deceased organ donation was included. All types of participants were 
included; for example, patients, healthcare professionals and the general public. Excluded from this review were interventions not conducted in a primary care setting, those not targeting organ donation nor those targeting living organ donation.

\section{Data sources and searching strategy}

Electronic databases searches were conducted from $27 / 11 / 2016$ to $19 / 07 / 2017$. The following electronic databases were selected for search; PsycINFO, CINAHL, Medline, Scopus, Web of Science and Global Health using the search string: (((Organ OR transplant)) AND intervention*) AND (GP OR "general pract*" OR "family medicine" OR physician* OR "primary care"). Ethos was also searched using the string; organ donation AND primary care. The reference lists of papers that passed all inclusion criteria were hand searched and authors of included studies contacted alongside other experts in the field both in the UK and internationally regarding studies for inclusion.

One reviewer (CPJ) screened articles by their title and subsequently by abstract if applicable. Full-text articles were obtained of studies meeting eligibility criteria following abstract and title review, and of those for which eligibility could not be established. A second reviewer read the full-text to determine eligibility. A third author not part of the original review process was available to resolve any disputes. The number of articles screened at all stages can be viewed in the PRISMA Flow Diagram (Figure 1) [17]. 


\section{Data Extraction and Management}

Eligible primary outcomes were actual behaviour of organ donor register sign up or conversation with family taking place. Secondary outcomes included were split into the following categories; Intention - to donate, sign-up or discuss with family members, and cognitive - improvement in knowledge, attitude change, identification or improvement in barriers and facilitators to donation. The lead author extracted data using an excel spreadsheet with the following columns; title, author, date of publication, language, aims, hypotheses, design, sample details (size, method), intervention design \& timescale, intervention theory, intervention target group (patients/staff), intervention target gender, intervention target participant age, intervention target participant ethnicity, intervention target participant socioeconomic status (SES: if applicable; patient gender, patient age, patient ethnicity, patient SES), attrition, outcome, outcome measures, analysis method, outcome results, other results, limitations, other comments. Records of searches were stored and duplicates removed using Endnote Desktop version X7.

\section{Quality Assessment}

Quality assessment was performed on all studies included for analysis, using the Cochrane recommended 'Assessment tool for Quantitative studies' published by the 'Effective Public Health Practice Project' [18-20]. This tool assesses studies according to selection bias, study design, confounders, blinding, data collection methods, withdrawals and drop-outs, intervention integrity and analyses. Component ratings are calculated according to these scores and studies are categorised as strong, moderate or weak. Strong studies had no weak ratings, moderate studies had one weak rating and weak studies had two or more weak ratings. 
Analysis

Due to the variation in reporting of outcome measures (independently verified sign-up versus self-reported sign-up and intention to sign-up) and the lack of any outcome data in one study, a meta-analysis was considered inappropriate. Narrative synthesis was chosen to best investigate the data, and the studies were analysed according to type of intervention.

\section{Results}

\section{Description of studies}

Electronic and hand-searches identified 3185 studies, reduced to 1407 after duplicates were removed (Figure 1). Title and abstracts were screened according to the inclusion criteria; 1395 records were excluded at this stage. Full-text assessment on ten articles led to the exclusion of two articles which were not conducted in a primary care setting (Siegel et al., 2008 [21] naturalistic settings and Manyalich et al. 2013 [22] healthcare workers in various settings across Europe), therefore ten studies were included in the final review. These consisted of two theses (Pradeep, 2014 [23] \& Faudree, 2010 [24]) four peer-reviewed journal articles (Thornton et al., 2016 [25], Bidigare \& Ellis, 2000 [26], Salim et al., 2014 [27] \& Natt et al., 2017 [28]) two conference presentations identified through correspondence with experts in the field (Degenholtz et al., [29] \& Razdan et al., [30]), one student presentation (Rocque, 2017 [31]) and one unpublished study conducted by NHS Blood and Transplant (NHSBT; Asghar [32]). One hundred percent agreement for eligibility between the first and second reviewer was established. 
Included Studies

The characteristics of included studies can be seen in Table 1. Included studies were conducted between 2000 and 2017 in either the U.K (Pradeep, 2014 [23] \& Asghar [32]). or U.S.A (Faudree, 2010 [24], Thornton et al., 2016 [25], Bidigare \& Ellis, 2000 [26], Salim et al., 2014, [27], Natt et al., 2017 [28], Degenholtz et al., [29], Razdan et al., [30] \& Rocque 2017 [31]). Studies were randomised control trials (RCTs) (Thornton et al., 2016 [25] \& Degenholtz et al [29]), non-randomised controlled trials (Bidigarre et al. 2000 [26]), interrupted time series (Salim et al., 2015 [27]) and one-group cohort studies (Pradeep, 2014 [23], Faudree, 2010 [24], Natt et al., 2017 [28], Razdan et al., [30], Rocque, 2017 [31] \& Asghar [32]). Five interventions focused on training staff as well as targeting patients (Pradeep, 2010 [23], Faudree, 2010 [24], Degenholtz et al [29], Razdan et al., [30] \& Asghar [32]) and five encouraged donation only through intervention with patients (Thornton et al., 2016 [25], Bidigare et al., 2000 [26], Salim et al., 2015 [27], Natt et al., 2017 [28], Rocque, 2017 [31]) . The primary outcome of nine included studies was actual registration as organ donors (Pradeep, 2014 [23], Faudree, 2010 [24], Thornton et al., 2016 [25], Bidigare \& Ellis, 2000 [26], Salim et al., 2014, [27], Natt et al., 2017 [28], Degenholtz et al., [29], Razdan et al., [30] \& Asghar [32]) and intention to register as an organ donor in one study (Rocque, $2017[31])$.

[Table 1] 


\section{Excluded Studies}

Two studies that were entered into the full-text screening stage were excluded from analysis as they were not conducted in a primary care setting. Siegel et al. [21] in hospital, library, community college and university settings, and Manyalich et al., [22] conducted across all health professionals involved in donation and transplant processes.

\section{Quality Assessment}

The methodological quality of included studies varied from strong to weak, see Table 2. Seven studies were classed as 'weak' (Pradeep [23], Faudree [24], Bidigare et al [26], Salim et al., [27], Razdan et al., [30], Rocque [31] \& Asghar [32]). Natt et al. [28] as 'moderate', Thornton et al. as [25] 'strong', and Degenholtz et al., [29] 'strong' for its primary outcome of organ donation registration but 'moderate' for its assessment of physician and staff knowledge and attitudes. The latter two studies were randomised controlled trials, reporting clearly on participant detail, with well-matched groups, and valid and reliable measures of organ donation registration (Thornton et al., [25] \& Degenholtz et al [29]). Natt et al., (2017, [28]) a one-group cohort study was rated moderate due to clear reporting of dropout-rates and data collection methods, but lack of reporting of potential confounders. Five of the weak studies were one group cohort studies (Pradeep, 2014 [23], Faudree, 2010 [24], Razdan et al., [30], Rocque, 2017 [31] \& Asghar [32]), one an interrupted time series (Salim et al., 2015 [27]), and one a controlled clinical trial with no randomisation of participants (Bidigare et al., 2000 [26]). The weak studies also either did not report on possible confounders or note withdrawals and drop-outs during intervention. However, five rated weak weak' (Pradeep [23], Faudree [24], Bidigare et al [26], Salim et al., [27], Razdan 
et al., [30], \& Asghar [32]) did use direct sign-up to an organ donor registry through form completion except Rocque who used intention to register [31].

[Table 2]

\section{Effects of intervention}

In eight out of the nine studies who used actual organ donor registration as their primary outcome, an increase in organ donation registration occurred (Faudree, 2010 [24], Thornton et al., [25], Bidigare et al., 2000 [26], Salim et al., 2014 [27], Natt et al., 2017 [28], Degenholtz et al., [29], Razdan et al., [30] \& Asghar [32]). However, this increase varied in size depending on the type of intervention applied. Rocque (2017 [31]) did not find an increase in intention to register as an organ donor. A summary of the results can be seen in Table 3.

[Table 3]

Active versus Passive Patient Interventions

All the interventions used to target patients can be categorised into 'active' (i.e. those that involve discussion, prompting, engagement or encouragement of donation) and 'passive' (i.e. those where printed materials were displayed but relied on the patients' approach). These were either combined i.e. active methods as intervention arm and passive as control, or evaluated in isolation. 
One passive only study (Pradeep, 2014 [20]) did not report any new registrations to the U.K. organ donation register after conducting their intervention, which consisted of health professional training and printed materials being made available for patients. The author also reported challenges to intervention implementation, mainly GPs and practice managers' concerns about resources. She states that although initially an active intervention was planned, the GP's would not implement it and requested passive materials be used instead.

An additional study also found no effect of the intervention, through intention to register. Rocque $(2017,[31])$ implemented an active intervention where patients attending a primary care clinic for their annual check-up were provided with an information sheet and survey. Only 6 participants took part, with an average intention to register score of 2.5 (Based on 15 Likert Scale, 1 is Very Unlikely and 5 is Very Likely). Qualitative outcomes were also examined, barriers included a belief that organs would not be usable $(\mathrm{N}=3 / 6,50 \%)$ and participants requiring more time to consider their decision ( $N=2 / 6,30 \%)$. Rocque, however highlights that further research is required due to the low $\mathrm{N}$ recruited to this study.

An active intervention by Natt et al $(2017,[28])$ also used information sheets and pamphlets, and included a donor registration form. Of those patients who returned the registration forms ( $\mathrm{N}=46 / 60,76.6 \%)$ an increase in registration to become an organ donor was found $(\mathrm{N}=11 / 39,28.3 \%)$. Participants served as their own control by disclosing their organ donor registration status prior to completing the intervention. Compared to baseline $(6 / 60,10 \%)$ the authors report an increase of registration rate by $18.3 \%$ in those who returned the form and were not already registered $(N=11 / 39,28.3 \%)$. As above however, 
the authors critique the generalisability of this study due to the low number of participants recruited.

Thornton et al. [25] utilised an active intervention where patients viewed a five-minute video to encourage donation then were asked to select a question about organ donation to ask their physician. This intervention resulted in a greater number of participants signing-up to be organ donors than compared to the control arm of usual care $(N=100 / 456,22 \%$ versus $\mathrm{N}=71 / 459,15 \%$ respectively; adjusted odds ratio (OR), 1.50 (95 \% Cl, 1.10-2.13). Differences were also found for organ donation knowledge scores post-intervention, with $16 \%$ higher knowledge in participants who had discussed organ donation with their physician compared to participants in the control group.

Asghar et al. [30] also implemented an active intervention, involving 'prompted choice' in one U.K. primary care practice. This pilot one group cohort study trained practice staff in organ donation, who then asked patients if they would like to register on the NHS ODR. Over a four-month period, $39 \%(\mathrm{~N}=277 / 703)$ of patients asked agreed to join the NHS ODR. A high proportion of uptake was noted among groups who are underrepresented on the NHS ODR [16] [33], including 55\% ( $\mathrm{N}=152)$ of over 50 s and $16 \%(\mathrm{~N}=46)$ from Black, Asian, and minority ethnic communities. Six out of forty-nine practices expressed an interest in taking part in the study, with barriers expressed by the practice staff concerning resources and time to devote to the intervention. 
Combining both active methods and passive materials and one group cohort design, Faudree [24] implemented a brochure-based intervention, given to those attending a military primary care centre by their physician at time of their annual check-up. Patients could request more information about organ donation and were asked for their donation intentions during their clinic appointment, post-brochure being given. Out of the 94 who were not already donors, 42 (21\%) decided to donate post-intervention.

Also combining these strategies, Salim et al. [27] examined the influence of staffed (active) and unstaffed (passive) kiosks containing pamphlets, posters and sign-up forms. During the staffed period of one week, 102 people signed up to become donors, significantly more than during the unstaffed period of six weeks where two people signed up (Unstaffed: 0.03 per 1,000 [95\% Cl: 0.0-0.1]. Staffed: 10 per 1,000 [95\% Cl: 8-13]; $p<.0001)$. However, Bidigare et al.[26], found no significant difference in sign-up between those who received passive printed material exposure combined with discussion with their physician and those who received passive material alone. Furthermore, the authors report results could be contaminated as ethically they were unable to control for participants in the passive arm initiating discussion with their physician concerning organ donation. Finally, Degenholtz et al's [28] three-arm randomised controlled trial used an intervention involving physician and staff training, using passive materials as their control. Posters and pamphlets promoting organ donation only saw no new registrations in the control arm. 
Primary Care Physician and Staff Training

Five studies investigated the role of primary care physician and staff training on registration. As previously stated, Pradeep [23] did not observe any new sign-ups to the register when training and passive printed media were introduced into five U.K. GP practices. However, the results by Asghar et al. [30] and Faudree [24] and Degenholtz et al [28] large scale randomised control trial contradict these results. A pilot study by Razdan preceded this RCT [29] working with a USA based primary care clinic to redesign the workflow and train staff in organ donation. This redesign caused patients to be presented with information and sign-up forms at clinic check-in and caused 29/444 (6.5\%) previously unregistered patients to signup. These results were used as the basis for Degenholtz et al. [28] study across 121 clinics with a total of 20,000 patient encounters over the trial period. Three arms were introduced, in-person training, web-based training and a control arm with posters and brochures for patients only. 225 people signed up in the web training condition ( $N=225 / 7950,7.1 \%), 536$ in in-person training ( $N=536 / 13,239,8.6 \%)$ and, crucially, no new sign-ups were recorded in the control arm. Both clinics with web and in-person training had sign up rates higher than control. Staff knowledge and attitudes were also examined; the intervention arms significantly improved knowledge (Web average knowledge score 10.35/15, in-person $10.21 / 15)$ compared to the control arm $(8.54 / 15, p<0.001)$ and in-person training caused significantly higher positive attitudes $(4.51 / 5)$ than both web-training $(4.4 / 5, p=0.01)$ and control $(4.28 / 5, p<0.001)$, with web-training also significantly higher than control $(p=0.04)$.

\section{Discussion}

To the best of our knowledge, this systematic review is the first examining organ donation interventions in primary care. Ten studies were identified which assessed the effectiveness 
of various types of intervention to increase sign-up rates to the organ donation registry, in the UK and USA. All but two of these studies identified an increase in sign-up rates post intervention; however, the ability to attribute this to a particular intervention methodology was limited. Two studies by the same research team focused on educating primary care professionals across multiple clinics. These proved significantly more successful in comparison to control groups of no education. Positive results were also found for interventions that employed discussion with physician or active in-person recruitment techniques in this setting. In contrast, those studies using passive methods where patients must be self-motivated and approach materials themselves had lower rates of sign-up to the register. Although a limited number of studies were found, this latter finding was strong and consistent throughout included interventions. Using active and passive methods to encourage other health behaviours also support the findings of this review [34-39].

A strong body of evidence supports the use of active methods of recruitment to organ donation registers in other settings, specifically the Driving Motor Vehicles (DMV) offices in the U.S.A. Numerous studies have investigated how to improve sign-up rates in this setting, the majority of which have found success [40-53]. The generalisability of these studies internationally however, is challenging, due to the unique nature of the DMV to the U.S.A. The studies reviewed in the present paper, indicate that primary care could provide the setting through which active interventions, like those investigated in the DMV, could be implemented internationally. Primary care settings are usually the first point of contact for patients with their health service and thus provide an opportunity for large numbers of people targeted through active intervention [54]. 
Due to the small number of studies and mixed quality assessment results found, there is uncertainty as to whether these results would be replicated in future studies however. Further, although positive support for passive methods has also been found, often previous studies do not compare passive to an active intervention group [55]. Two studies examining sedentary behaviour compared passive and active methods, with passive posters at the point of behaviour increasing target behaviour levels alongside active methods [56-57]. The implication for the current review is that although active interventions are superior, passive methods could be successfully used alongside the active at the point of behaviour and should not be discarded altogether.

A theoretical explanation for these results comes from the IIFF model of organ donation registration behaviour by Siegel, Alvaro and Hohman (2010, [58]). The IIFF model stands for, Immediate sign-up opportunity, Information provision, Focused Engagement and Favourable activation. The authors state all of these factors must be included simultaneously for registration behaviour to take place. A key element in the successful studies reviewed in the current paper is the opportunity to undertake the behaviour immediately after or during exposure to the intervention. The authors propose it is this element which differentiates the unsuccessful passive and successful active organ donation interventions in this review.

It is important to note however that throughout the studies reported, no capture rate of passive interventions was provided. It is possible therefore that the superior findings for 'active' studies could be due to poor intervention fidelity of passive interventions, rather than poor efficacy of the materials themselves. Passive materials could have been displayed 
in ways which caused them to be ignored or not noticed by participants [59-61]. This could also be explained by the IIFF model, where focused engagement or a participant engaging with the passive intervention materials, does not occur due to their placing in a primary care setting. Previous research has found that placing of passive materials in primary care is often inappropriate and healthcare professionals themselves are often not aware of their presence [59].

Implications for Practice

The results of this review indicate that the use of passive posters, brochures and pamphlets as organ donation interventions in primary care settings are likely to be ineffective on their own. These passive approaches, although cost-effective should be combined with active methods to encourage donation if an increase in donor registrations is desired. Previous investigations into the use of posters and leaflets in primary care has been conducted at length, with a lack of leaflet display fidelity, concern over patient perceptions and lack of patient engagements with leaflets being reported to be key barriers to implementation [5961]. The active methods to promote organ donation registration used in eight of the studies contained in this review have the potential to help combat these barriers. By directly engaging with patients concerning organ donation fidelity issues such as patient exposure or poster placement are lessened. Training healthcare professionals in organ donation communication could also aid with these barriers by lessening any embarrassment or fear of negative patient perceptions through providing communication strategies and tools. 
Implications for Research

Two high quality RCTs show positive results for intervention in this setting, with regard to staff training on registration rates and direct patient intervention $[25,29]$. However, five studies were of low quality and one moderate. Therefore, it is recommended that further high quality research is needed before firm conclusions of intervention efficacy can be made. Further, barriers expressed by Pradeep [20] and Asghar et al. [26] suggest that a primary care setting, although potentially effective, may not be feasible for large scale intervention roll out. Of note, Pradeep [20] was the only study to find no new sign-ups postintervention. Although poorly scored in the quality assessment, the author attributed these results to expressed time constraints, causing barriers to access and implementation by the practice managers and GPs themselves. To combat barriers of the type expressed by Asghar et al., [26] and Pradeep [20], Razdan et al., [24] incorporated a collaborative workflow rearrangement to include organ donation sign-up forms as part of general practice. This was well received by the pilot clinic and the authors did not anticipate additional burden by including this. These results are promising and suggest a collaborative approach to intervention development between researchers and general practice could be successful.

It should also be stated that although some positive results have been found in this context, the feasibility of this environment for intervention has yet to be investigated fully by any study. Therefore, recommendations are made for future studies to assess the feasibility of primary care as a setting for organ donation interventions, prior to intervention efficacy assessment. 
Increasing rates of organ donation is vitally important to counter the discrepancy between donation rates and those awaiting transplant. By examining interventions previously conducted, effective methods and settings can be determined. This review focuses on organ donation interventions in primary care settings and found 10 eligible studies, nine targeting actual organ donor register sign-up and one intention to sign-up. Successful interventions were found to utilise active methods of participant engagement that encourage donation at the point of contact. Passive methods such as leaflets, posters and those with which the participant has to actively engage show less promising results. Combining active and passive strategies along with primary care staff training is recommended, however, this review highlights the potential barriers to implementation in primary care and the dearth of research assessing the feasibility of this setting for organ donation interventions.

\section{Acknowledgements}

The authors thank Zeeshan Asghar and NHS Blood and Transplant for their continued support on this project. Thanks also go to Professor Howard Degenholtz, for kindly providing the results of his research. Finally, thanks go to Professor Ronan Carroll, Dr. Agimol Pradeep, Professor John D. Thornton for their correspondence and assistance with data collection. 


\section{References}

[1] Rudge C, Matesanz R, Delmonico FL, Chapman J. International practices of organ donation. Br J Anaesth 2012;108:i48-55. doi:https://doi.org/10.1093/bja/aer399.

[2] NHS Blood and Transplant. Organ Donation and Transplantation - Activity figures for the UK as at 7 April 2017. https://nhsbtdbe.blob.core.windows.net/umbraco-

assets/1343/annual stats.pdf; 2017 [Accessed 26th April 2017].

[3] Organ Procurement and Transplant Network. National Data.

https://optn.transplant.hrsa.gov/data/view-data-reports/national-data/\#; 2017 [Accessed July 20, 2017]

[4] Shepherd L, O'Carroll RE, Ferguson E. An international comparison of deceased and living organ donation/transplant rates in opt-in and opt-out systems: a panel study. BMC medicine. 2014 Sep 24;12(1):131. doi: 10.1186/s12916-014-0131-4

[5] Hulme W, Allen J, Manara AR, Murphy PG, Gardiner D, Poppitt E. Factors influencing the family consent rate for organ donation in the UK. Anaesthesia 2016;71:1053-63. doi:10.1111/anae.13535.

[6] Johnson RJ, Bradbury LL, Martin K, Neuberger J. Organ Donation and Transplantation in the UK-The Last Decade. Transplant J 2014;97:S1-27.

doi:10.1097/01.TP.0000438215.16737.68.

[7] Douville F, Godin G, Vézina-Im L-A. Organ and tissue donation in clinical settings: a systematic review of the impact of interventions aimed at health professionals. Transplant Res 2014;3:8. doi:10.1186/2047-1440-3-8.

[8] Andrew L, Michelle I, Stephen J, Allison T, Kirsten H, Li A, et al. Interventions To Increase Willingness For Deceased Organ Donation: A Systematic Review. Immunol Cell Biol 2013;91:A6.

[9] Li AH, Rosenblum AM, Nevis IF, Garg AX. Adolescent classroom education on knowledge and attitudes about deceased organ donation: a systematic review. Pediatr Transplant 2013;17:119-28. doi:10.1111/petr.12045.

[10] Morgan S, Miller J, Arasaratnam L. Signing cards, saving lives: An evaluation of the worksite organ donation promotion project. Commun Monogr 2002;69:253-73. doi:http://dx.doi.org/10.1080/03637750216540.

[11] Salim A, Bery C, Ley EJ, Schulman D, Navarro S, Zheng L, et al. A focused educational program after religious services to improve organ donation in Hispanic Americans. Clin Transplant 2012;26:E634-40. doi:10.1111/ctr.12036.

[12] Hafzalah M, Azzam R, Testa G, Hoehn KS. Improving the potential for organ donation in an inner city Muslim American community: the impact of a religious educational intervention. Clin Transplant 2014;28:192-7. doi:10.1111/ctr.12296.

[13] Conesa C, Ríos A, Ramírez P, Sánchez J, Sánchez E, Fernández OM, et al. Rural primary care centers as a source of information about organ donation. Transplant. Proc., vol. 37, Elsevier; 2005, p. 3609-13. doi:http://doi.org/10.1016/j.transproceed.2005.08.060.

[14] Deedat S, Kenten C, Morgan M. What are effective approaches to increasing rates of organ donor registration among ethnic minority populations: a systematic review. BMJ Open 2013;3:e003453. doi:http://dx.doi.org/10.1136/bmjopen-2013-003453.

[15] Hippisley-Cox J, Vinogradova Y. Trends in consultation rates in general practice 1995 to 2008: Analysis of the QResearch database.

http://www.hscic.gov.uk/catalogue/PUB01077/tren-cons-rate-gene-prac-95-09-95-08rep.pdf.; 2009 [Accessed 26th April 2017]. 
[16] NHS Blood and Transplant. Organ Donation and Transplantation Activity Report 2016/17. https://nhsbtdbe.blob.core.windows.net/umbraco-assets-

corp/4505/activity report 2016 17.pdf; 2017 [Accessed July 20, 2017].

[17] Moher D, Liberati A, Tetzlaff J, Altman DG, Grp P. Preferred Reporting Items for Systematic Reviews and Meta-Analyses: The PRISMA Statement (Reprinted from Annals of Internal Medicine). Phys Ther 2009;89:873-80. doi:10.1371/journal.pmed.1000097.

[18] Thomas BH, Ciliska D, Dobbins M, Micucci S. A process for systematically reviewing the literature: providing the research evidence for public health nursing interventions. Worldviews Evidence-Based Nurs 2004;1:176-84. doi:10.1111/j.1524-475X.2004.04006.x. [19] Armijo-Olivo S, Stiles CR, Hagen NA, Biondo PD, Cummings GG. Assessment of study quality for systematic reviews: a comparison of the Cochrane Collaboration Risk of Bias Tool and the Effective Public Health Practice Project Quality Assessment Tool: methodological research. J Eval Clin Pract 2012;18:12-8. doi:10.1111/j.1365-2753.2010.01516.x.

[20] Effective Public Health Practice Project (EPHPP). Quality Assessment Tool For Quantitative Studies 2010. http://www.ephpp.ca/tools.html [accessed April 22, 2017].

[21] Siegel JT, Alvaro EM, Crano WD, Lac A, Ting S, Jones SP. A quasi-experimental investigation of message appeal variations on organ donor registration rates. Heal Psychol 2008;27:170-8. doi:10.1037/0278-6133.27.2.170.

[22] Manyalich M, Guasch X, Paez G, Valero R, Istrate M. ETPOD (European Training Program on Organ Donation): a successful training program to improve organ donation. Transpl Int 2013;26:373-84. doi:10.1177/0017896914559854.

[23] Pradeep A. Increasing organ donation from the North West South Asian community through targeted education. University of Salford, United Kingdom, 2014.

[24] Faudree CB. Impact of a primary care based organ donation practice initiative on individual willingness to donate organs. University of South Carolina, United States of America, 2010.

[25] Thornton JD, Sullivan C, Albert JM, Cedeno M, Patrick B, Pencak J, et al. Effects of a Video on Organ Donation Consent Among Primary Care Patients: A Randomized Controlled Trial. J Gen Intern Med 2016;31:832-9. doi:10.1007/s11606-016-3630-5.

[26] Bidigare SA, Ellis AR. Family physicians' role in recruitment of organ donors. Arch Fam Med 2000;9:601.

[27] Salim A, Berry C, Ley EJ, Schulman D, Anderson J, Navarro S, et al. Improving organ donor registration using kiosks in primary care clinics. Health Educ J 2014;74:758-63. doi:10.1177/0017896914559854.

[28] Natt N, Klar E, Cheung I, Matharu P, Bordman R. Increasing Organ Donor Registration in a Primary Care Clinic. BMJ quality improvement reports. 2017 Apr 1;6(1):u222401-w8341.

[29] Degenholtz H, Creppage K, Shaw Y, Burns S, Oyebode S, Enos M. Patients Save Lives: Organ and Tissue Donor Designation in the Primary Care Setting. n.d. Unpublished.

[30] Razdan M, Degenholtz H, Himber M, Lazzara K, Resnick A, Wells S, et al. Controlled trial of academic detailing and web-based education for primary care physicians to increase donor designations: results from pilot testing. n.d. Unpublished.

[31] Rocque B. Identification of barriers to organ donation: A primary care interventional approach. Family Medicine Block Clerkship, Student Projects. 223. 2017.

http://scholarworks.uvm.edu/fmclerk/233. [Accessed July 20 2017]

[32] Asghar Z, NHS Blood and Transplant. GP Surgeries Trial - "Prompted Choice": Increasing registrations to the NHS Organ Donor Register n.d. Unpublished.

[33] NHS Blood and Transplant. Organ Donation and Transplantation data for 
Black, Asian and Minority Ethnic (BAME) communities: Report for 2016/2017. 2017. https://nhsbtdbe.blob.core.windows.net/umbraco-assets-

corp/4480/bame organ donation and transplantation data.pdf [Accessed July 20 2017]

[34] Albarracín D, Gillette JC, Earl AN, Glasman LR, Durantini MR. Prevention Interventions Since the Beginning of the Epidemic. Psychol Bull 2005;131:856-97. doi:10.1037/0033-2909.131.6.856.A.

[35] Fisher JD, Fisher WA. Theoretical approaches to individual-level change in HIV risk behavior. Handb. HIV Prev., Springer; 2000, p. 3-55. doi:10.1007/978-1-4615-4137-0_1.

[36] Johnson DF, Sorvillo FJ, Wohl AR, Bunch G, Harawa NT, Carruth A, et al. Frequent failed early HIV detection in a high prevalence area: implications for prevention. AIDS Patient Care STDS 2003;17:277.

[37] Kalichman SC, Carey MP, Johnson BT. Prevention of sexually transmitted HIV infection: A meta-analytic review of teh behavioral outcome literature. Ann Behav Med 1996;18:6-15. doi:10.1007/BF02903934.

[38] Dolan A, Staples V, Summer S, Hundt GL. "You ain"t going to say... I've got a problem down there': workplace-based prostate health promotion with men. Health Educ Res 2005;20:730-8. doi:https://doi.org/10.1093/her/cyh033.

[39] Summer S, Dolan A, Thompson V, Hundt G. Prostate health awareness-promoting men's health at work. Mens Heal J 2002;1:146-9.

[40] Harrison TR, Morgan SE, Corcia MJ. Effects of information, education, and communication training about organ donation for gatekeepers: clerks at the Department of Motor Vehicles and organ donor registries. Progress in Transplantation. 2008 Dec;18(4):3019.

[41] Harrison TR, Morgan SE, King AJ, Williams EA. Saving lives branch by branch: the effectiveness of driver licensing bureau campaigns to promote organ donor registry sign-ups to African Americans in Michigan. Journal of health communication. 2011 Sep 1;16(8):80519.

[42] Harrison TR, Morgan SE, King AJ, Di Corcia MJ, Williams EA, Ivic RK, Hopeck P. Promoting the Michigan organ donor registry: evaluating the impact of a multifaceted intervention utilizing media priming and communication design. Health communication. 2010 Nov 30;25(8):700-8.

[43] Thornton JD, Alejandro-Rodriguez M, León JB, Albert JM, Baldeon EL, De Jesus LM, Gallardo A, Hossain S, Perez EA, Martin JY, Lasalvia S. Effect of an iPod Video Intervention on Consent to Donate OrgansA Randomized Trial. Annals of internal medicine. $2012 \mathrm{Apr}$ 3;156(7):483-90.

[44] Salim A, Malinoski D, Schulman D, Desai C, Navarro S, Ley EJ. The combination of an online organ and tissue registry with a public education campaign can increase the number of organs available for transplantation. The Journal of trauma. 2010 Aug;69(2):451.

[45] Rodrigue JR, Krouse J, Carroll C, Giery KM, Fraga Y, Edwards E. A Department of Motor Vehicles intervention yields moderate increases in donor designation rates. Progress in Transplantation. 2012 Mar;22(1):18-24.

[46] King AJ, Williams EA, Harrison TR, Morgan SE, Havermahl T. The "Tell Us Now" campaign for organ donation: using message immediacy to increase donor registration rates. Journal of Applied Communication Research. 2012 Aug 1;40(3):229-46.

[47] Quick B, Harrison TR, King AJ, Bosch D. It's up to you: a multi-message, phased driver facility campaign to increase organ donation registration rates in Illinois. Clinical transplantation. 2013 Sep 1;27(5). 
[48] Rodrigue JR, Fleishman A, Fitzpatrick S, Boger M. Organ donation knowledge, willingness, and beliefs of motor vehicle clerks. Transplantation. 2014 Nov 27;98(10):1025-8. [49] Degenholtz HB, Resnick A, Tang Y, Razdan M, Enos M. Effect of Web-Based Training for Department of Motor Vehicle Staff on Donor Designation Rates: Results of a Statewide Randomized Trial. American Journal of Transplantation. 2015 May 1;15(5):1376-83.

[50] Siegel JT, Tan CN, Rosenberg BD, Navarro MA, Thomson AL, Lyrintzis EA, Alvaro EM, Jones ND. Anger, frustration, boredom and the Department of Motor Vehicles: Can negative emotions impede organ donor registration?. Social Science \& Medicine. 2016 Mar 31;153:174-81.

[51] Rodrigue JR, Fleishman A, Fitzpatrick S, Boger M. Organ donation video messaging in motor vehicle offices: results of a randomized trial. Progress in Transplantation. 2015 Dec;25(4):332-8.

[52] Feeley TH, Anker AE, Evans M, Reynolds-Tylus T. A Department of Motor VehicleBased Intervention to Promote Organ Donor Registrations in New York State. Progress in Transplantation. 2017 Jul 4:1526924817715471.

[53] DuBay DA, Ivankova N, Herby I, Schoenberger YM, Redden DT, Holt C, Siminoff L, Fouad $M$, Martin MY. Factors Perceived to Influence the Decision for African Americans to Become Registered Organ Donors at the Department of Motorized Vehicles. Journal of the National Medical Association. 2017 May 5.

[54] Hippisley-Cox, J. \& Vinogradova, Y. (2009) Trends in consultation rates in general practice 1995/1996 to 2008/2009: analysis of the QResearch database. 2009.

http://www.hscic.gov.uk/catalogue/PUB01077/tren-cons-rate-gene-prac-95-09-95-08rep.pdf. [Accessed July 20 2017].

[55] llic D, Rowe N. What is the evidence that poster presentations are effective in promoting knowledge transfer? A state of the art review. Heal Inf Libr J 2013;30:4-12. doi:10.1111/hir.12015.

[56] Olander EK, Eves FF. Effectiveness and cost of two stair-climbing interventions-less is more. Am J Heal Promot 2011;25:231-6. doi:10.4278/ajhp.090325-QUAN-119.

[57] Cheung PPY, Chow BC, Parfitt G. Using Environmental Stimuli in Physical Activity Intervention for School Teachers: A Pilot Study. Int Electron J Health Educ 2008;11:47-56.

[58] Siegel JT, Alvaro EM, Hohman ZP. A dawning recognition of factors for increasing donor registration. Understanding Organ Donation Applied Behavioral Science Perspectives. Chichester, UK: John Wiley \& Sons. 2010 Jan 6:313-30.

[59] Freeman E, Howell-Jones R, Oliver I, Randall S, Ford-Young W, Beckwith P, et al. Promoting chlamydia screening with posters and leaflets in general practice-a qualitative study. BMC Public Health 2009;9:383. doi:10.1186/1471-2458-9-383.

[60] McClinchy J, Dickinson A, Barron D, Thomas H. Practitioner and lay perspectives of the service provision of nutrition information leaflets in primary care. J Hum Nutr Diet 2011;24:552-9. doi:10.1111/j.1365-277X.2011.01200.x.

[61] Gignon M, Idris H, Manaouil C, Ganry O. The waiting room: vector for health education? the general practitioner's point of view. BMC Res Notes 2012;5:511.

doi:10.1186/1756-0500-5-511. 


\section{Figures}

Figure 1: PRISMA Flow Diagram of Search Results.

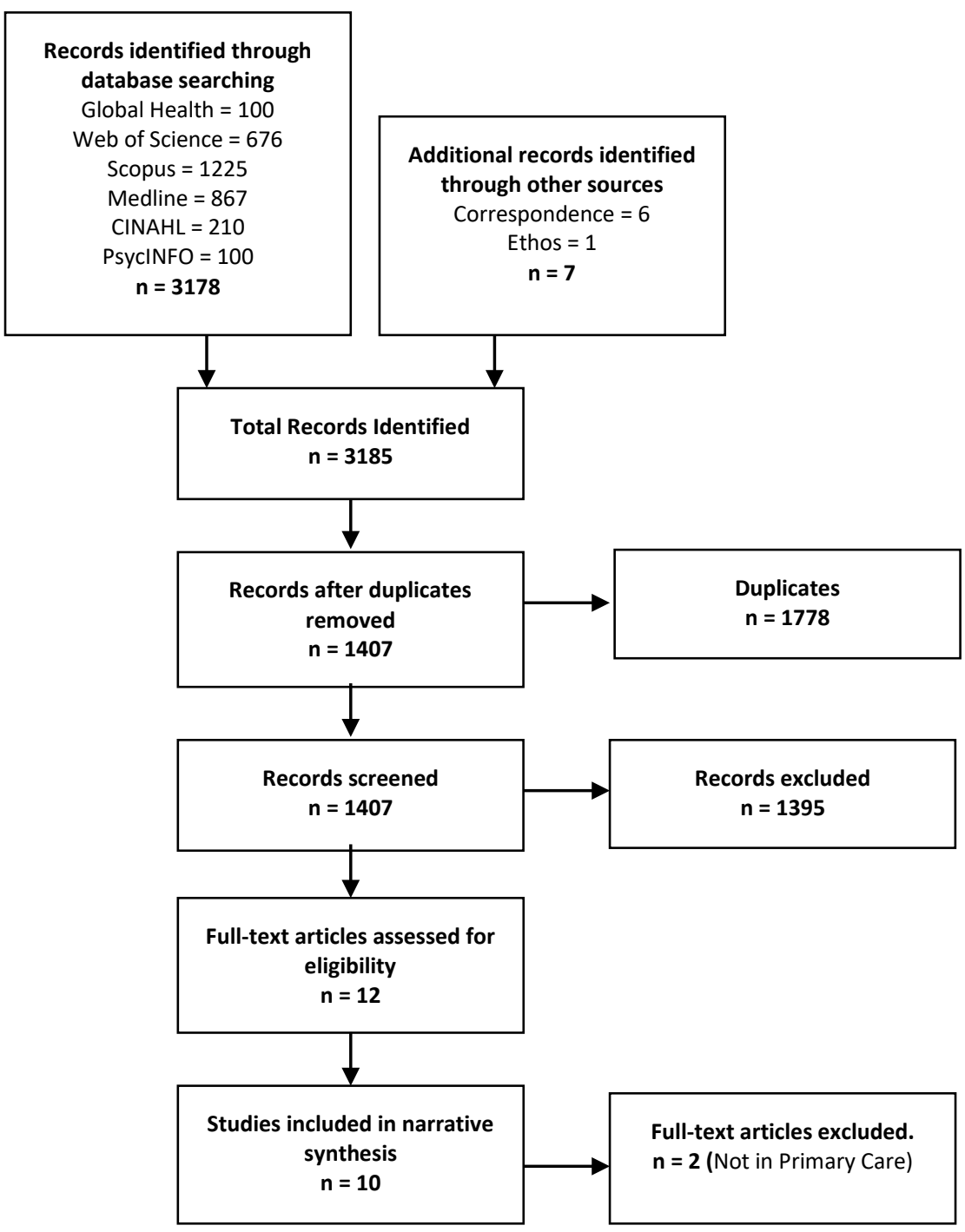


Tables

Table 1: Characteristics of included studies.

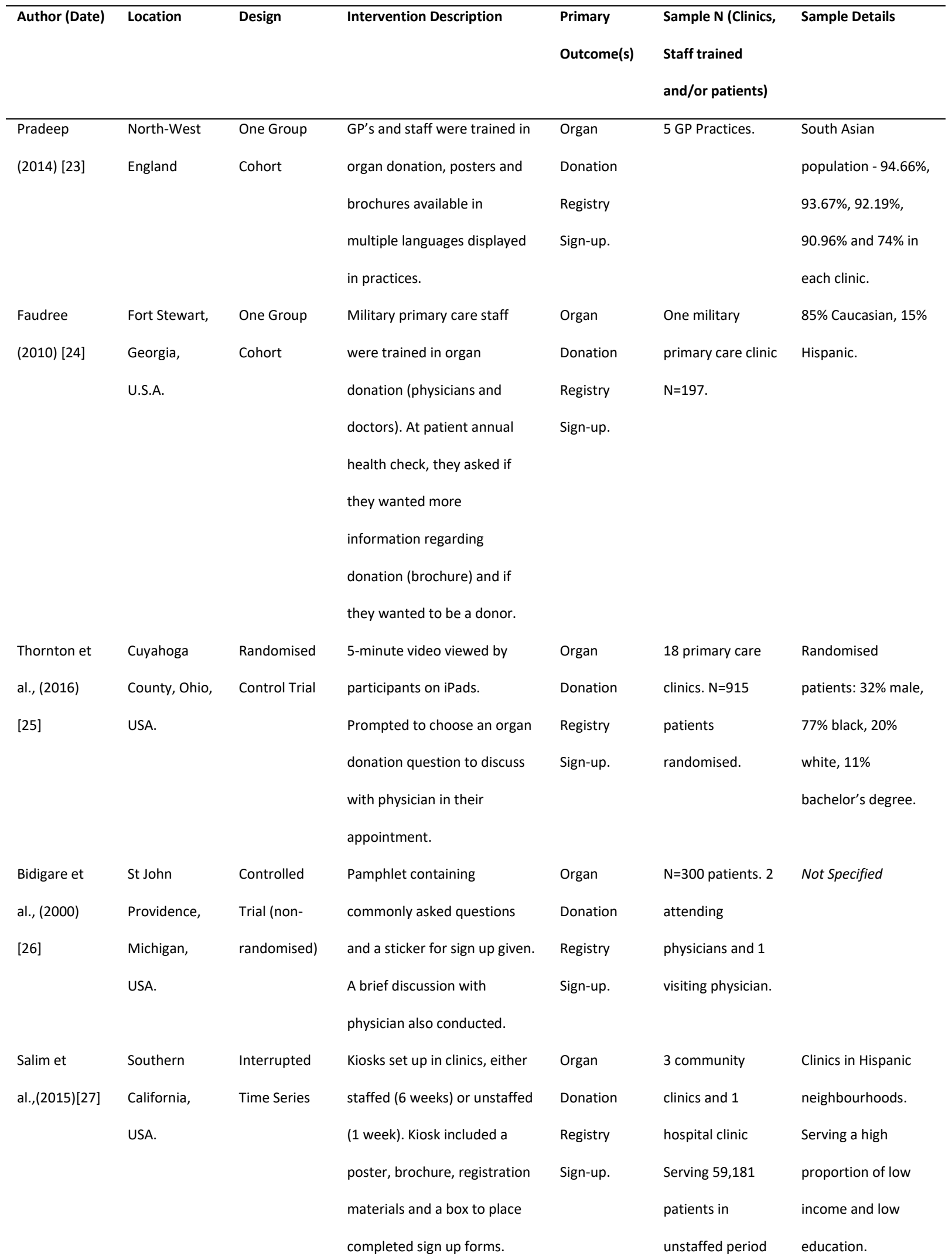




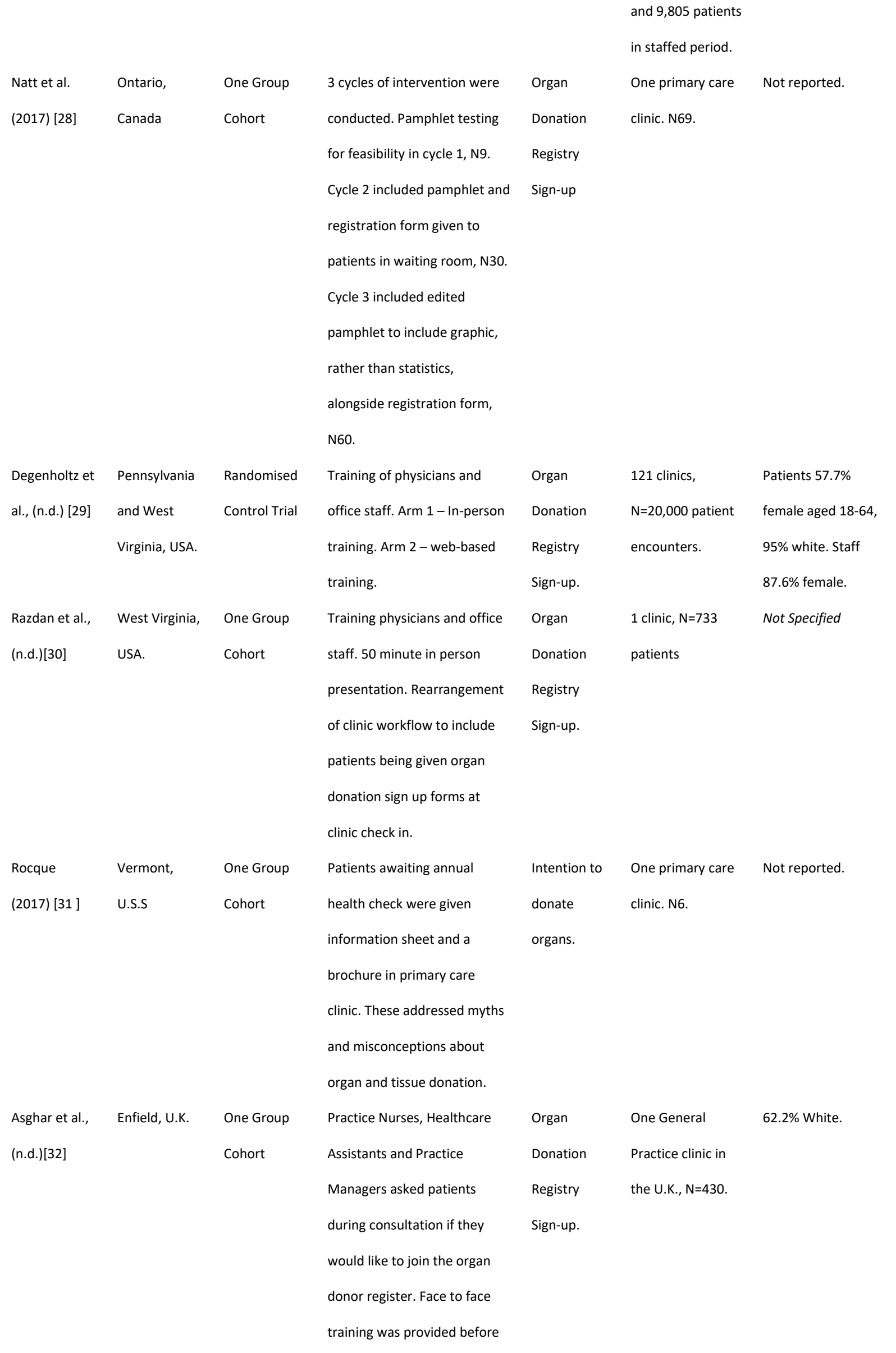


Table 2: Quality assessment of included studies in our review, using Assessment tool for Quantitative studies [20].

\begin{tabular}{|c|c|c|c|c|c|c|c|}
\hline \multirow[t]{3}{*}{ Author } & Selection & Study & Confounders & Blinding & Data & Withdrawals & Global \\
\hline & \multirow[t]{2}{*}{ Bias } & \multirow{2}{*}{\multicolumn{2}{|c|}{ Design }} & & Collection & and & \multirow[t]{2}{*}{ Rating } \\
\hline & & & & & Methods & Dropouts & \\
\hline Pradeep [23] & Moderate & Moderate & Moderate & Moderate & Weak & Weak & WEAK \\
\hline Faudree [24] & Moderate & Moderate & Weak & Moderate & Weak & Weak & WEAK \\
\hline Thornton et al. [25] & Moderate & Strong & Strong & Moderate & Strong & Strong & STRONG \\
\hline Bidigare et al. [26] & Weak & Weak & Moderate & Moderate & Moderate & Weak & WEAK \\
\hline Salim et al. [27] & Moderate & Moderate & Weak & Moderate & Strong & Weak & WEAK \\
\hline Natt et al [28 ] & Moderate & Moderate & Weak & Moderate & Strong & Moderate & MODERATE \\
\hline \multirow[t]{2}{*}{ Degenholtz et al. [29] } & Moderate & Strong & Strong & Moderate & Moderate & Strong & STRONG/ \\
\hline & & & & & & & MODERATE \\
\hline Razdan et al. [30] & Weak & Moderate & Strong & Moderate & Moderate & Weak & WEAK \\
\hline Rocque [31] & Weak & Moderate & Weak & Moderate & Weak & Weak & WEAK \\
\hline Asghar et al. [32] & Moderate & Moderate & Weak & Moderate & Strong & Weak & WEAK \\
\hline
\end{tabular}


Table 3: Results of included studies.

\begin{tabular}{|c|c|c|c|}
\hline Author (Date) & $\begin{array}{l}\text { Primary } \\
\text { Outcome }\end{array}$ & Sample & Results Summary \\
\hline Pradeep (2014) [23] & $\begin{array}{l}\text { Actual } \\
\text { registration }\end{array}$ & 5 GP Practices & No new registrations to the U.K. NHS Organ Donor Register. \\
\hline Faudree (2010) [24] & $\begin{array}{l}\text { Actual } \\
\text { registration }\end{array}$ & N94 & $21 \%$ registered post intervention. \\
\hline Thornton et al., (2016) [25] & $\begin{array}{l}\text { Actual } \\
\text { registration }\end{array}$ & $\begin{array}{l}\text { Intervention Arm N456, } \\
\text { Control arm N459. }\end{array}$ & $\begin{array}{l}\text { Intervention arm resulted in higher sign-up than control arm } \\
\text { (22\% versus } 15 \%) \text {. }\end{array}$ \\
\hline Bidigare et al., (2000) [26] & $\begin{array}{l}\text { Actual } \\
\text { registration }\end{array}$ & N176 & $\begin{array}{l}40 \% \text { of patients decided to become organ donors post } \\
\text { intervention. }\end{array}$ \\
\hline Salim et al.,(2015)[27] & $\begin{array}{l}\text { Actual } \\
\text { registration }\end{array}$ & $\begin{array}{l}\text { Staffed patient encounters } \\
\text { N 9,805 } \\
\text { Unstaffed patient } \\
\text { encounters N 59,181 }\end{array}$ & $\begin{array}{l}\text { Significantly more people registered during staffed kiosk period } \\
\text { than unstaffed ( } 102 \text { people versus } 2 \text { people). }\end{array}$ \\
\hline Natt et al. (2017) [28] & $\begin{array}{l}\text { Actual } \\
\text { registration }\end{array}$ & N39 & $\begin{array}{l}\text { Increase in registration to become a donor by } 18.3 \% \text { compared } \\
\text { to participant's registration status prior to intervention. }\end{array}$ \\
\hline Degenholtz et al., (n.d.) [29] & $\begin{array}{l}\text { Actual } \\
\text { registration }\end{array}$ & $\begin{array}{l}\text { Patient encounters } \\
\mathrm{N} 20,000\end{array}$ & $\begin{array}{l}7.1 \% \text { signed up to register in web training condition, } 8.6 \% \\
\text { signed up in in-person training and no new registrations were } \\
\text { found in control condition. }\end{array}$ \\
\hline Razdan et al., (n.d.)[30] & $\begin{array}{l}\text { Actual } \\
\text { registration }\end{array}$ & N444 & $6.5 \%$ patients signed up to organ donor register. \\
\hline Rocque (2017) [31 ] & $\begin{array}{l}\text { Intention to } \\
\text { register }\end{array}$ & N6 & $\begin{array}{l}\text { On Likert scale } 1 \text { - very unlikely to register and } 5 \text { - very likely to } \\
\text { register. Average intention to register score } 2.5 \text {. }\end{array}$ \\
\hline Asghar et al., (n.d.)[32] & $\begin{array}{l}\text { Actual } \\
\text { registration }\end{array}$ & N703 & $39 \%$ of patients joined NHS Organ Donor Register. \\
\hline
\end{tabular}


Keywords

Organ Donation, Systematic review, Primary Care, Interventions, Organ Donation Registration. 